\title{
Tax Credits Response to Tax Enforcement: Evidence from a Quasi-Experiment in Chile
}

\author{
Claudio A. Agostini* \\ Universidad Adolfo Ibañez
}

Claudia Martínez A.

Universidad de Chile

January 2013

\begin{abstract}
Diesel in Chile receives a different tax treatment depending on its use. If diesel is used in industrial activities the diesel taxes paid can be fully used as a credit against VAT, but if it is used in freight or public transportation -basically trucks and buses- only a fraction of diesel taxes paid can be claimed as a tax credit for VAT payments. As a result of this different tax treatment firms have incentives to use "tax exempted" diesel in activities requiring "non tax exempted" diesel. This tax wedge, therefore, generates an opportunity for tax evasion, especially for firms with multiple economic activities, one of them being transport. In this paper we analyze the impact of a tax enforcement program implemented by the Chilean IRS, where letters requiring information about diesel purchases and use and vehicles ownership were sent to around 200 firms in 2003. Using different empirical strategies to consider the non-randomness of the selection of firms, the empirical results show consistently that firms receiving a letter decreased their diesel tax credits by around $10 \%$.
\end{abstract}

JEL: H26, H32

Keywords: diesel tax, tax evasion, tax enforcement, Chile

\footnotetext{
*Agostini: claudio.agostini@uai.cl, Martínez A.: cmartineza@econ.uchile.cl. We thank Guido Imbens, Joel Slemrod, Jeff Smith, and seminar participants at the University of Michigan for valuable comments and suggestions. We also thank Servicio de Impuestos Internos for access to the data and the funding provided by the Research Grant Fondecyt 1110542. Javiera Selman provided excellent research assistance.
} 


\section{Introduction}

Gasoline and diesel are subject to specific taxes and VAT in Chile, but diesel is taxed at a much lower rate. Gasoline tax is equivalent to US\$1.27 a gallon while diesel tax is just US\$0.43 a gallon. Additionally, because diesel is used as a main input in several industrial activities it receives a special tax treatment depending on its use. Specifically, if diesel is used in industrial activities the diesel tax paid can be used as a tax credit against VAT and if diesel is used in freight or public transportation (basically trucks and buses) only a fraction of the diesel taxes paid can be used as a tax credit against VAT. As a result of this different tax treatment firms have incentives to use "tax exempted" diesel in activities requiring "non tax exempted" diesel. This might be easier to do for multi-product firms using diesel for several activities, allowing them to evade diesel taxes by claiming larger amounts of tax credits than what is legally allowed. A similar practice was detected in the U.S. during the 80 s where firms were buying exempted fuel to be used for on-road tax activities, in which case is was not exempted, and then created several transactions among related firms to hide the tax evasion, a practice known as “daisy chain” (Marion and Muehlegger (2008)). ${ }^{1}$

In 2003 the Chilean IRS implemented a special auditing plan to detect diesel tax evasion and improve tax enforcement. For this purpose, the IRS selected first the firms that had the largest changes in diesel tax credits claimed between 2001 and 2002 and sent them a letter asking to voluntarily report more details of every diesel transaction during the last two and half years. In October of 2003, 205 firms received the letter asking them to submit the required information within the next 30 days. The IRS received some information from 183 firms and, after checking the information sent by the firms, only 66 of them were selected for an exhaustive and mandatory audit. This special enforcement plan was implemented only once in October 2003. There were neither other enforcement actions nor tax changes during this period of time.

In this paper we use monthly data from October 2002 to September 2004, for firms claiming diesel tax credits in all sample periods, to estimate the impact of receiving the IRS letter requesting information related to diesel purchases, vehicles owned, and tax credits claimed. Firms receiving the letter could have perceived its message as an increase in the

\footnotetext{
${ }^{1}$ More specifically, firms purchased untaxed diesel fuel and resold it to affiliates to make it more difficult to audit the transaction. Then the affiliate resold the diesel to retail gas stations as diesel for which taxes had been collected.
} 
probability of being detected, which should have decreased their evasion activities (Allingham and Sandmo (1972), Sheffrin and Triest (1992)). The dataset used for the empirical analysis contains detailed information about many relevant dimensions for each firm: size based on sales (very small, small, medium and large), number of different economic activities, tax regime (accrual based accounting, cash flow accounting, presumptive tax regime), and the year the firm started its operations.

One of the main difficulties in identifying the effects of receiving the letter from the IRS is that firms were not randomly selected to receive it. As a matter of fact, the firms receiving the letter are quite different from the firms not receiving it in some observable dimensions that might potentially be correlated with tax evasion. For example, $66 \%$ of the firms to which the IRS sent letters were large firms, while only $16.1 \%$ of the ones not receiving it were large; all of them are under accrual accounting tax reporting regime, compared to only $55.1 \%$ among firms that did not receive the letter. ${ }^{2}$

Even though the firms were not randomly selected ${ }^{3}$ and the two groups actually differ in some relevant dimensions, we have the advantage of knowing the selection criterion used by the IRS to choose the firms to which send the letter to. ${ }^{4}$ The IRS ranked the firms based on their changed in tax credits claimed between 2002 and 2001 and sent a letter to the first 205 firms with the largest change. Therefore, the empirical strategy we use to identify the effects of the letter on the diesel tax credit claims by the firms consists of two steps. First, we balance the sample using a propensity score method such that notified and not notified firms are similar in observable characteristics. Considering the selection process we cannot achieve total balance, but the matching allows to compare across firms that are in the common support. Second, using this subsample we estimate a difference in difference impact of the letter controlling for the selection process implemented by the IRS to choose the "treated" firms. The selection equation is estimated using the change in the amount of tax credits

${ }^{2}$ In some other dimensions the two groups of firms are not too different, for example $36.6 \%$ of the firms receiving the letter have only one economic activity and $55 \%$ are more than 10 years old, compared to $39.9 \%$ and $52 \%$ among the firms not receiving the letter respectively.

${ }^{3}$ Given that the assignment to treatment conditions was not random, the identification strategy used in this paper is different from the one used in the literature of tax evasion based on experimental methods (Kleven et al. (2011), Fellner et al (2009), Wenzel and Taylor (2004), Slemrod et al. (2001))

${ }^{4}$ Although the non-random selection creates a potential bias that needs to be controlled for, it prevents the problems with the Taxpayer Compliance Measurement Program (TCMP) studies where taxpayers were aware that the selection was random (Long and Schwartz (1987). 
claimed by each firm between 2002 and 2001. The results of the estimation indicate that receiving the letter reduced diesel tax claims by $10 \%$.

In general, the empirical results show a significant impact of the letter sent by the IRS asking firms to voluntarily report some information on their diesel tax credits- in reducing the amount of tax credits claimed by firms. These results are consistent with other results in the literature showing that just receiving a letter from the IRS has an impact on tax compliance because it causes a substantial increase in the perceived detection risk (Fellner et al (2009)). In that sense, the results show that the IRS in Chile can successfully reduce diesel tax evasion by affecting firms' perceived cost on non-compliance. However, it is important to interpret this result as a short-term impact of receiving a letter from the IRS once, which might differ or not from either a long-run impact or receiving multiple IRS letters over time.

Most of the empirical evidence in the tax evasion literature has focused on individual's compliance for income taxes in developed countries. This paper contributes to the empirical literature on tax evasion and enforcement providing evidence about firm's compliance of diesel taxes in a developing country.

The paper continues as follows. Section 2 describes in detail fuel taxes in Chile. Section 3 explains the diesel tax enforcement program implemented by the IRS. Section 4 describes the data and the empirical strategy used in the empirical analysis. Section 5 shows and discusses the empirical results. Section 6 presents a robustness analysis of the main results. Finally, Section 6 concludes.

\section{Fuel Taxes in Chile}

Fuel taxes were enacted in Chile in 1986, justified as an instrument to finance road construction, especially after a strong earthquake that struck the country in 1985. It is a specific tax collected by the seller at the first sell or import. The diesel tax rate is four times lower than the gasoline tax rate with a rate of $1.5 \mathrm{UTM}$ by $\mathrm{m} 3$, equivalent to 0.44 US dollars per gallon, as opposed to 6 UTM by $\mathrm{m} 3$ for gasoline. ${ }^{5}$ The gasoline tax is high relative to the

\footnotetext{
${ }^{5}$ The monthly tax unit (UTM) is an index used to maintain the value of taxes in constant money. In December 2012, one UTM was worth Ch\$40,206, around 85 US dollars.
} 
United States, but not relative to Europe, while the diesel tax (for transportation) is relatively low.

Currently, there exists two regimes establishing diesel tax credits. Initially, when the diesel tax was enacted in 1986, there was a unique regime establishing that firms could claim a tax credit for $100 \%$ of diesel taxes paid if diesel is used in activities different from transportation on public roads. Under this regime passenger transport and trucking firms were explicitly not allowed to claim diesel tax credits. Then, starting in October 2001, a second regime was created for the trucking industry allowing firms to claim a tax credit for a share of their diesel purchases. More specifically, the new regime established that firms owning or leasing trucks with a gross weight of 3.86 tons or higher could claim $25 \%$ of their diesel tax paid as a tax credit against the VAT. However, the recovery rate of diesel taxes was increased to $80 \%$ from July 2008 to June 2009 after hundreds of trucks blocked the main highway for 3 days requesting subsidies from the government to compensate the spike in oil prices. ${ }^{6}$ Then, on July 2009, the Law No. 20.360 established a recovery rate based on annual sales. Firms with annual sales below 18.600 UTM can claim as a tax credit $80 \%$ of their diesel tax paid, firms with sales above 18,600 UTM and below 42,500 UTM can claim 50\%, and firms with sales above 42,500 UTM can claim $38 \%$.

To summarize, currently there is a general regime allowing firms a $100 \%$ recovery rate for diesel taxes paid from diesel used as an input in all their economic activities except transportation on public roads, and a special regime for trucking firms allowing them a recovery rate between $38 \%$ and $80 \%$ depending on their sales. Under both regimes firms can claim diesel tax credits together with their monthly VAT payments.

Tax revenue, credit claims and the number of firms claiming the tax credit have changed over time because of changes in diesel prices and regulation, even though the diesel tax rate has not changed since its enactment in 1986. The diesel tax revenue increased between 2000 and 2009 by $97.9 \%$, while over the same time period, diesel VAT credits increased by $192.3 \%$. The percentage of diesel taxes paid that can be claimed as VAT credit

${ }^{6}$ The Law No. 19.764 established a phase-in period of 3 years for the diesel tax credit. The share of the diesel tax paid that could be claimed as tax credit was $10 \%$ in $2001-2002,20 \%$ in 2003 and $25 \%$ since January 2004. Then, the Law No. 20.278 increased the share to $80 \%$ for the period between July 2008 and June 2009. 
has been raised from $48.06 \%$ to $70.9 \%$ during the same period. Absent of a diesel price change, the recovery rate (VAT credit / diesel tax revenue) of each firm should be constant over time unless there is either a change in their productive process modifying the amount of diesel used or a normative change. For the firms analyzed in the study there is neither relevant policy changes in regulation nor in enforcement activities during the years of analysis, except for the IRS letter explicitly considered.

The recovery rate can also be affected by changes in consumer behavior, namely tax avoidance and evasion. The diesel tax credit creates a wedge in diesel prices depending on its use: there is a price for diesel used in transportation, a lower price for diesel used in the trucking sector and an "tax free" price for diesel used in manufacturing. These different prices generate incentives to use "tax exempted" diesel in activities that should pay diesel tax. The fact that there is no third-party reporting associated to diesel taxes in Chile might exacerbate the incentives to evade or avoid the tax as it has been empirically shown in many studies for other countries (Klepper and Nagin (1989), Long and Swingden (1990), Christian (1994), Andreoni et al (1998), Slemrod (2007)).

Evasion of diesel taxes can mostly occur through claiming more tax credits than what firms are eligible for. There are at least four mechanisms for doing it that have been detected over time by the Chilean IRS. First, firms with multiple economic activities can buy diesel for their non-transport activities but use it for their transport operations. Second, nontransport firms can hire a transport firm, a trucking company for example, and pay for the transport services with diesel instead of money. If the two firms have a common owner these type of transaction are even easier to do. Third, transportation firms claim diesel tax credits for all their operations, national and international transport services, not only for the diesel used in their national operations which is what they are legally allow to do. Fourth, diesel purchased by a firm for its operations is also used in diesel cars of the owners and managers of the firm and tax credits are claimed for all diesel purchases made by the firm. Some of these mechanisms were suspected by the IRS, which motivated the implementation of a special enforcement program for diesel taxation with the main goal of reducing its evasion.

\section{The Diesel Tax Enforcement Program}

In October of 2003, exactly two years after the diesel tax credit system started, the Chilean IRS implemented a special auditing plan to detect diesel tax evasion and improve tax 
enforcement. The IRS selected the firms that had the largest changes in the tax credits reported between December 2001 and December 2002 and sent them a letter asking to report more details on every diesel transaction. The letter said:

"The IRS will start an auditing program for taxpayers claiming diesel tax credits. For this reason you should send the following information to the IRS:

-Diesel purchases between January 2001 and August 2003

-Diesel tax paid

-Quantity and fraction of diesel used by vehicles

-List and registration number of vehicles owned by the firm, including year, maker, model, mpg and monthly miles traveled.

The requirement to send this information does not imply you are going to be audited. In case your firm is selected for a detailed auditing you will receive a new letter from the IRS."

During October of 2003, 205 firms received the letter asking them to submit the requested information within the next 30 days. As it was mentioned before, firms were chosen according to their previous increase in diesel tax credits claimed. The reason to choose firms based on the level change in tax credits, as oppose to percent change for example, is related to the IRS incentives for increasing revenue with their enforcement actions. The Ministry of Finance pays an annual bonus, to be distributed among IRS employees, based on tax revenue increases due to IRS enforcement. Therefore, all the enforcement actions implemented by the IRS have usually the goal of detecting large amounts of tax evasion more than catching taxpayers evading a large fraction of the taxes they should pay. In other words, for the IRS catching one taxpayer evading $10 \%$ of a large amount of taxes owed is more attractive than catching one taxpayer evading $100 \%$ of a small amount.

Using the IRS data we replicate their decision rule, ranking the firms according to their level change of tax credits claimed between December 2002 and December 2001. Although the IRS criterion was to send letter the top 200 firms in this ranking, the data shows 
that the letter was not sent to 22 of the top 200 firms $^{7}$ and it was sent to 20 firms that were not in the top $200 .{ }^{8}$ Apparently, the reason for the exclusion of 22 firms was an administrative problem with the mailing address and, as a result, the IRS decided to send the letter to the next 20 firms in the ranking.

The IRS received some type of information from 183 firms out of the 205 that received the letter and after revising the information sent by the firms, 66 firms were selected for an exhaustive and mandatory audit. The small number of audited firms, as well as the lack of information on their selection, prevents a consistent econometric identification of its impact. Furthermore, we do not know the date on which each firm was audited. However, as a complimentary analysis to the letter impact, the empirical section of the paper also includes an estimation of the letter impact on audited firms. What is important to highlight, for the purpose of identifying the effects of the letter and the audits, is that this special enforcement and auditing plan was implemented only once in October 2003.

Theoretically, the letter sent by the IRS could potentially reduce the amount of tax credits claimed by firms after receiving it. Marion and Muehlegger (2008) using a simple model, where firms choose the fraction of untaxed diesel purchases they use to produce output conditional on their evasion cost, show that an increase in the probability of auditing by the IRS reduces the fraction of untaxed diesel purchases by the firms. If the letter sent by the IRS had the effect of increasing the perceived probability of being audited by the firms, then the amount of tax credits claimed should have decreased from evading firms. The empirical question then is whether this happened or not and up to what extent.

\section{Empirical Strategy}

\subsection{Data}

We have access to IRS monthly data for 21,876 firms claiming diesel tax credits at least once from October 2002 to April 2004. After doing a basic and minimum cleaning (dropping duplicate observations and also firms with missing diesel tax claims and missing economic sector) the number of firms is reduced to 17,071, of which 198 were notified. However, we decided to consider in the empirical analysis only those firms that claimed diesel tax credits

${ }^{7}$ Firms ranked in places 2,3,6,11,29,30,34,38,62,69,77,79,100, 115, 123, 147, 150, 153, 175 , 193, and 196.

${ }^{8}$ Ranked 202 to 223 , except 210 . 
every month during this period (19 months), which reduces to 3,461 the number of firms, of which 105 received the IRS letter. The main reason to consider only firms regularly claiming diesel tax credits is to focus on the intensive margin response to the letters sent by the IRS. ${ }^{9}$

Firms on four economic sectors as their main activity were included in the enforcement program: transportation (except passenger transportation firms because they cannot claim diesel tax credits), manufacturing, commerce and construction. The data includes sales, VAT credits and debits, diesel credits, economic sector, accounting system/tax regime, number of different economic sectors in which the firm has activities, age and size.

Table 1 shows summary statistics, separately for notified and not notified firms, of the data we use in the empirical analysis. Columns (1) and (2) reports the mean and standard deviation of the 3,461 firms included in the analysis, The average monthly diesel tax credit is 635,526 with a standard deviation of $\$ 4,842,650$ (in $\operatorname{logs} 11.23$ and 1.81 respectively. The letter was sent to $3.1 \%$ of all diesel tax credit firm claimers in the sample. The firms claiming diesel tax credits are mostly small firms (47.3\%) and large firms represent only $9.8 \% .{ }^{10}$ The main economic sector claiming tax credits is, as expected, transportation (76.9\%), followed by manufacturing and construction. Regarding the type of tax reporting, 56.4\% of the firms in the sample use accrual reporting and $33.7 \%$ pay according to presumptive tax. The average number of tax reported activities is 2.1 , with a maximum of 19 , and most of the firms are 10 years old or more.

Table 1 also shows firms' descriptive statistics by notification status -which is relevant to frame the empirical strategy- and the results of a t-test for the mean difference between notified and non-notified firms for each observable characteristic. Columns (3) and (4) report the mean and the standard deviation for not notified firms $(\mathrm{N}=3,356)$, and columns (5) and (6) for notified firms $(\mathrm{N}=105)$. The difference in means between not notified and

${ }^{9}$ One possible reaction to the IRS letter from firms not claiming diesel tax credits regularly could have been to start reporting diesel tax credits more often. If we include these firms in the analysis, there could be a spurious positive effect of the enforcement if the same tax credit amount is claimed spread out across more months as a result of the letter. In such case the average monthly claim after the enforcement would be smaller and, therefore, we are being conservative focusing only on firms claiming tax credits every month.

${ }^{10}$ The standard classification used by the government is based on annual sales: less than US $\$ 100,000$ are very small firms; between US $\$ 100,000$ and US $\$ 1,000,000$ are small firms; above US $\$ 1,000,000$ but below US $\$ 4,200,000$ are medium firms; and more than US $\$ 4,200,000$ are large firms. 
notified firms and its t test is reported in columns (7) and (8). Not surprisingly, because the letter was not sent to a random sample of firms, the t-tests show that notified and not notified firms are statistically different in several dimensions. Notified firms have more economic activities -which can give them more opportunities for evasion-, are more likely to be in construction or commerce as their main economic activity and less likely to be in transport, are less likely to be of small size and, as expected, have larger diesel tax credits. Interestingly, none of them file taxes either under a presumptive tax or cash-reporting regime. These large differences in observable firms' characteristics challenge the identification of the effect of the letter on the amount of diesel tax credits claimed by the firms receiving the IRS letter.

The most natural approach to estimate the effect of the letter is to use a difference-indifference estimator, comparing the behavior of not notified firms (control group) with the one of notified firms (treatment group) before and after the letter was sent. However, using observations in the control group that are not relevant comparisons can bias the results (Imbens at al (2001)). For example, as previously noticed, there are no observations in the notified group with presumptive tax, and therefore it is not relevant to have observations with this tax regime in the control group. This asymmetry in firms' characteristics also occurs in firms' size and age, as there are neither firms classified as "very small" nor with ages between 0 and 2 in the group notified. As an objective statistical method to keep only relevant observations and have a comparable control group, we use propensity score to define the control and treatment groups as suggested and implemented by Imbens and Wooldridge (2009) and Dehejia and Wahba $(1999,2002)$.

The propensity score has as dependent variable a dummy with the value of one if the firm was notified and zero if not. The regression is run using cross-sectional data for August 2003, before the letter was sent. The controls included are logarithm of diesel credit, number of activities, economic sector dummies, log of VAT and firm's age. The balancing property of the propensity score is only satisfied when the sample is restricted to the top 1,401 firms in the ranking constructed by the Chilean IRS to select firms to be notified. After computing the propensity score, only observations in the common support are kept in the sample of analysis, both in the treatment and control group. It is important to notice that the propensity score is only used to select the sample of analysis, but it is not used in the estimation. 
The number of observations in the control group in the common support sample is 464 and in the treatment group is 105 , slightly more than $50 \%$ of the total number of firms notified. Figure 1 shows the quarterly average diesel tax credits claimed by notified and not notified firms in the final sample of 569 firms used in the empirical analysis. As can be seen in the figure, there is a clear reduction in diesel tax credits claimed by the firms receiving the IRS letter just after receiving it, which is something that did not occur on firms not receiving the letter.

Figure 1: Quarterly Average Diesel Tax Credits, Final Sample

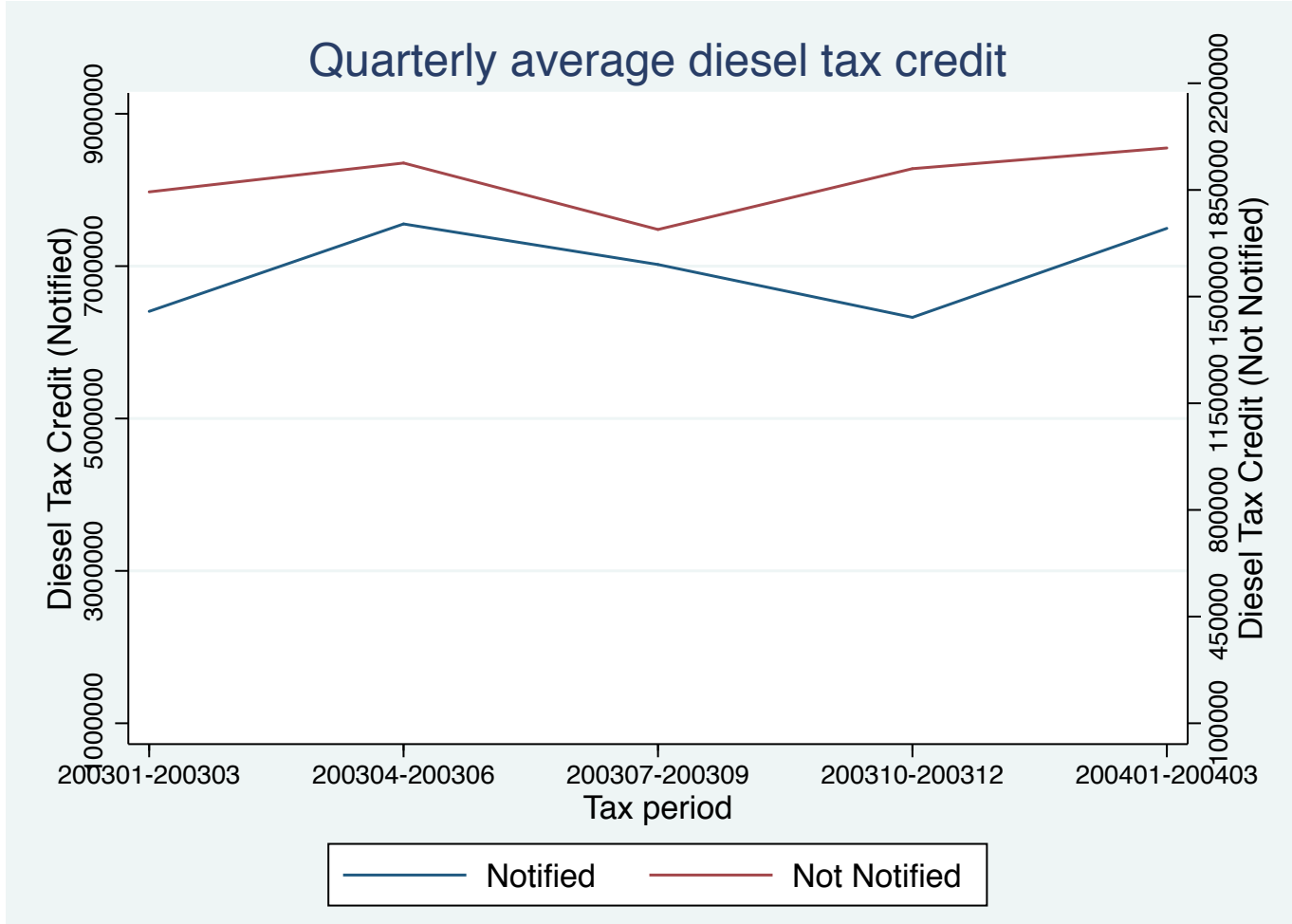

Table 2 shows the descriptive statistics for all firms in the common support of the sample. Differences between the treatment and control group are now reduced and even completely disappear for some variables. However, because some unobservable differences might still remain given the non-randomness of the treatment, the empirical strategy used to identify the effect of the IRS letter on the amount of diesel tax credits claimed should attempt to separate the effect of the letter from the potential effect on different underlying characteristics between notified and not notified firms. For this purpose, and based on this sample of 569 firms, each of them with 16 months of diesel tax credit information, we also 
use the selection criterion used by the IRS for notifying firms to estimate the impact of being notified.

\subsection{Econometric Specification}

As it was previously mentioned, the notified firms in the sample might not be comparable to the not notified firms even after considering only the observations in the common support. As a result, the difference in outcomes of treated and untreated firms might be biased as a measure of the effect of the enforcement program. To avoid this potential bias we consider two empirical strategies. First, we estimate the effect of the IRS letter with a difference in difference model using the following empirical specification:

$$
\text { TaxCredit }_{i t}=\beta_{0}+\beta_{1} T_{i} A_{t}+\beta_{2} T_{i}+\beta_{3} A_{t}+\beta_{4} X_{i t}+\varepsilon_{i t}
$$

where $T_{i}=1,0$ indicates if the firm was notified, $A_{i}=1,0$ indicates if the observation is before or after the letter was sent ${ }^{11}$, TaxCredit Th $_{i t}$ is the diesel tax credit (the outcome of interest) of firm $i$ in period $t$ and $X_{i t}$ a set of firm $i$ characteristics: number of activities, economic sector, VAT reported, firm age and firm size. This empirical strategy, which combines propensity score matching to have a comparable control group and a difference-indifference estimator to estimate the average impact of the treatment on the treated group, follows Caliendo and Kopeinig (2008) and its identification assumption is that notified and not notified firms have a parallel trend on their diesel tax credits.

The second empirical strategy adds a selection. Even though the firms were not randomly selected and the two groups actually differ in some relevant dimensions, as it is shown in Table 2, we know the selection criterion used by the IRS to choose which firms to send letters to. The unique criterion was to send letter to the top 200 firms with the largest changes in tax credits used between 2002 and 2001. Therefore, we can identify the effect of the letter on the diesel tax credit claims by the firms estimating a difference in difference impact between control and treatment groups considering the selection process implemented by the IRS to choose the "treated" firms. ${ }^{12}$ The selection equation is estimated considering 2004.

${ }^{11}$ The period before is January-September 2003 and the period after is October 2003-April

${ }^{12}$ In some studies using ordinary audits the selection is also endogenous but not known, which makes it difficult to control for the selection bias (Erard (1992)). 
the change in the amount of tax credit claimed by each firm between 2002 and 2001 . The empirical specification used is:

$$
\begin{aligned}
& \text { TaxCredit }_{i t}=\beta_{0}+\beta_{1} T_{i} A_{t}+\beta_{2} T_{i}+\beta_{3} A_{t}+\beta_{4} X_{i t}+\beta_{\lambda} I M R+\varepsilon_{i t} \\
& \operatorname{Pr}\left(T_{i}=1\right)=\alpha_{0}+\alpha_{1} \Delta \text { TaxCredit }_{i}+\alpha_{3} X_{i t}+u_{i}
\end{aligned}
$$

where $\Delta$ TaxCredit $_{\mathrm{i}}$ is the change in the total amount of diesel tax credits claimed between 2002 and 2001. Equation (3) is the selection equation and equation (2) is the difference and difference equation adding the Inverse Mills Ratio (IMR). The identification assumption is that notified and not notified firms have a parallel trend on their diesel tax credits considering their selection.

\section{Results}

\subsection{Main Effects}

Table 3 shows the results of estimating equation (1) using the panel of firms with random effects. ${ }^{13}$ The variable notification is a dummy equal to 1 for the firms receiving the IRS letter, the variable After Letter is a dummy equal to 1 for all the months after the letter was sent, and the variable Letter*After Letter is the interaction of the two variables whose coefficient represents therefore a difference in difference estimator.

The first column shows the results without any controls, column (2) adds month and year dummies, and column (3) includes additional explanatory variables related to firm characteristics. The difference in difference estimator is statistically significant and shows that receiving the IRS letter decreased the amount of tax credits claimed by the firms in $9.9 \%$, a result that is robust across all specifications.

Table 4 shows the results of estimating equations (2) and (3), which allows to eliminate the potential bias introduced by the non-random selection of firms. As in Table 3, the first column shows the results of the estimation without any controls; the second column includes months and year dummies in the regression; and the last column includes some firms' characteristics. The top panel in the table shows the treatment effect, where the

${ }^{13}$ The Wu-Hausman test does not reject random effects with respect to fixed effects. The point estimate using fixed effects is $-9.9 \%$, statistically significant. 
difference-in-difference estimator shows again a significant impact of the letter on diesel tax credit claims. On average, the letter reduced the amount of credits reported by the treated firms between 6.7 and $7.3 \%$. This result is quite robust across the different specifications and is not slightly lower in magnitude than the one estimated without a selection correction. The coefficient of the Inverse Mills ratio is statistically significant, implying a sample selection bias (Melino (1982)), and negative, indicating a negative correlation between unobservable variables in the selection equation and the outcome equation.

The bottom panel in the table shows the estimated selection equation, where it can be seen that the larger the level change in diesel tax credits claimed between 2002 and 2001, the more likely is that a firm would be notified. ${ }^{14}$

There are some other interesting patterns that emerge from these results. Firms in the economic sectors of manufacturing and transport claim more tax credits than the ones in services, the omitted category, and, on the contrary, firms in the construction economic sector claim less than the ones in services. Small and medium firms claim more diesel tax credits than large firms, which might be surprising but is consistent with similar patterns found by Kleven et al. (2002) and Pomeranz (2011), and younger firms -aged between 2 and 4 yearsclaim less tax credits.

We also consider the possibility that the letter would have reduced the amount of VAT credits claimed. For this purpose we estimated the equivalent to equations (1) and (2), but replacing diesel tax credits by VAT tax credits. The results, which are presented in Tables 7 and 8 in the Appendix, show that there is no impact of the IRS letter on the amount of VAT credits claimed by firms receiving the letter. This is an interesting and maybe surprising result because the tax form used to claim diesel tax credits is the same used to report VAT debits and credits. Therefore, a letter from the IRS asking for information about diesel tax credits claimed could have implied a potential audit of everything reported in the same tax form. If firms were over-reporting diesel tax credits they could have been over-reporting VAT credits too, in which case a potential impact of the letter would have been to reduce both. The empirical results, however, show an impact only on diesel tax credits reported. One potential explanation is that VAT has a self-enforcement mechanism and it is more difficult

${ }^{14}$ The selection equation is estimated also including the corresponding control variables considered in each specification, but the coefficients are not reported in the table. 
for firms to over-report credits because other firms are reporting equivalent debits (Agha and Haughton (1996), Kopczuk and Slemrod (2006)), which is consistent with the empirical results of Pomeranz (2011) for Chile. Another explanation is that firms believed that the IRS would potentially audit only the diesel tax credits, which is not unlikely as the IRS is organized in different auditing divisions for different taxes.

\subsection{Heterogeneous Effects}

Table 5 shows the results of considering heterogeneous treatment effects based on the main economic sector on which firms report activities: transportation, manufacturing and construction (the default sector is retail). All point estimates are positive, between 0.04 and 0.19 , however they are only significant for transportation and construction. These positive coefficients imply that the letter had a larger effect on retail. The estimation for the total effect (at the bottom of Table 5) shows that the specific industry effect is only relevant for manufacturing and it is not significant when all controls are included. This might be a result of having a small number of treated firms in the sample, which prevents an accurate identification of industry effects for all industries as standard errors increase when more interaction effects are included in the regressions.

We also try to identify separately the effect of the letter on single-industry firms with respect to multi-industry firms. The coefficient on the number of activities was large $(31 \%)$, negative and significant. However, the difference-in-difference estimator for multi-industry firms was not significant and of small magnitude (around -3.0\%). Again, it is difficult to know if the effect is truly zero or there are too few observations to identify it the potential additional impact of the letter on firms with more than one economic activity. ${ }^{15}$

15 Additionally, the lack of data prevents to identify the potential major effect of having economic activities in more than one sector, one of them being transport. A firm with activities in the transport sector and an additional economic sector could claim diesel tax credits in its other sector for diesel used in its transport activities. Therefore, the letter could have had an larger impact on firms having economic operations in the transport sector and also in another economic sector. However, the data reports only the main economic activity of each firm and the total number of economic activities in which has operations. Therefore, the data allows to identify only firms whose main economic sector is transport and also have economic activities in some other sector, but it is not possible to identify firms whose main economic activity is one different from transport but that also have transport activities. 


\section{Robustness}

It is important to discuss the main identification assumption in the empirical strategy we used, which is the existence of a similar trend between notified and not notified firms. The estimated treatment effect of the IRS letter relies on the idea that in the absence of the letter, there would be no different trends in the diesel tax credits claimed between notified and notnotified firms. We test this assumption doing a false experiment implemented with the data for the period before the notification. For this purpose, we estimated equations (1), (2), and (3) again but defining the dummy Notification as if the letter was sent in March. ${ }^{16}$ The results of this false experiment are reported in Table 6, which shows a non-significant treatment effect with a coefficient very close to zero for the difference-in-difference estimator.

In addition to the main identifying assumption, it is also important to consider robustness checks to the main empirical results related to the data used in the regressions and the decisions implemented to obtain the final sample used in the estimations.

Regarding the data, we used a sample of firms that claimed diesel tax credits every month during the period of analysis with the goal of focusing on intensive margin. Even though firms file VAT and diesel tax credits monthly, this decision might be considered arbitrary. To check the robustness of the results considering longer periods, we did the same empirical analysis using all firms claiming diesel tax credits every quarter instead of every month. The results show a larger impact of the IRS letter, around $-13 \%$, which is consistent with a potential additional impact on the extensive margin and firms spreading out across more months their diesel tax credits claims a result of the letter.

An additional restriction on the data was to use a sample of firms based on the results of the propensity score matching (PSM) to ensure comparability. If the sample before the PSM is used instead, the empirical results show an impact of the IRS letter ranging between 0.12 and -0.15 .

${ }^{16}$ The period after is, therefore, defined between March and August 2003. We also run false experiments choosing February or April as the month in which the letter was sent and the results did not change. 
One final robustness check related to the data used is to completely drop the monthly variation in tax credits claimed and estimate the effect of the IRS letter considering only two periods. If we collapse the monthly observations into two periods, pre- and post-treatment, the estimated effects of the IRS letter is a $-9.6 \%$ reduction in tax credits claimed.

Finally, it could be informative to consider that $32 \%$ of notified firms were also audited as part of the diesel enforcement program. The small number of firms and the lack of information on its selection mechanism and the date of the audits prevent a robust estimation of its effect. However, in Table 6 we present the results of estimating equation (1) restricting the sample to notified firms. In this case, the difference-in-difference estimator is based on considering the audited firms as the treatment group and the firms receiving the letter but not audited as the control group. The point estimate ranges between $-5 \%$ and $-7 \%$, but it is not statistically significant, which is not at all surprising considering the small number of firms included in this exercise $(\mathrm{N}=190)$. If we consider this result as a consistent estimate of the auditing on tax credits claimed, the effect of the letter found in the previous section could be interpreted as a combination of the notification and an audit for a fraction of the notified firms. However, some caution is needed in interpreting this estimate. More specifically, it is not clear that this a consistent estimator of the effect of the audit on firms for two reasons. First, the selection criteria for choosing the firms to be audited it is not known and we do not have access to the information sent by the firms in response to the IRS letter. Second, it is not known either when the firms were audited, which makes impossible to determine the after treatment period. 
Figure 2: Monthly Diesel Tax Credits Notified Firms

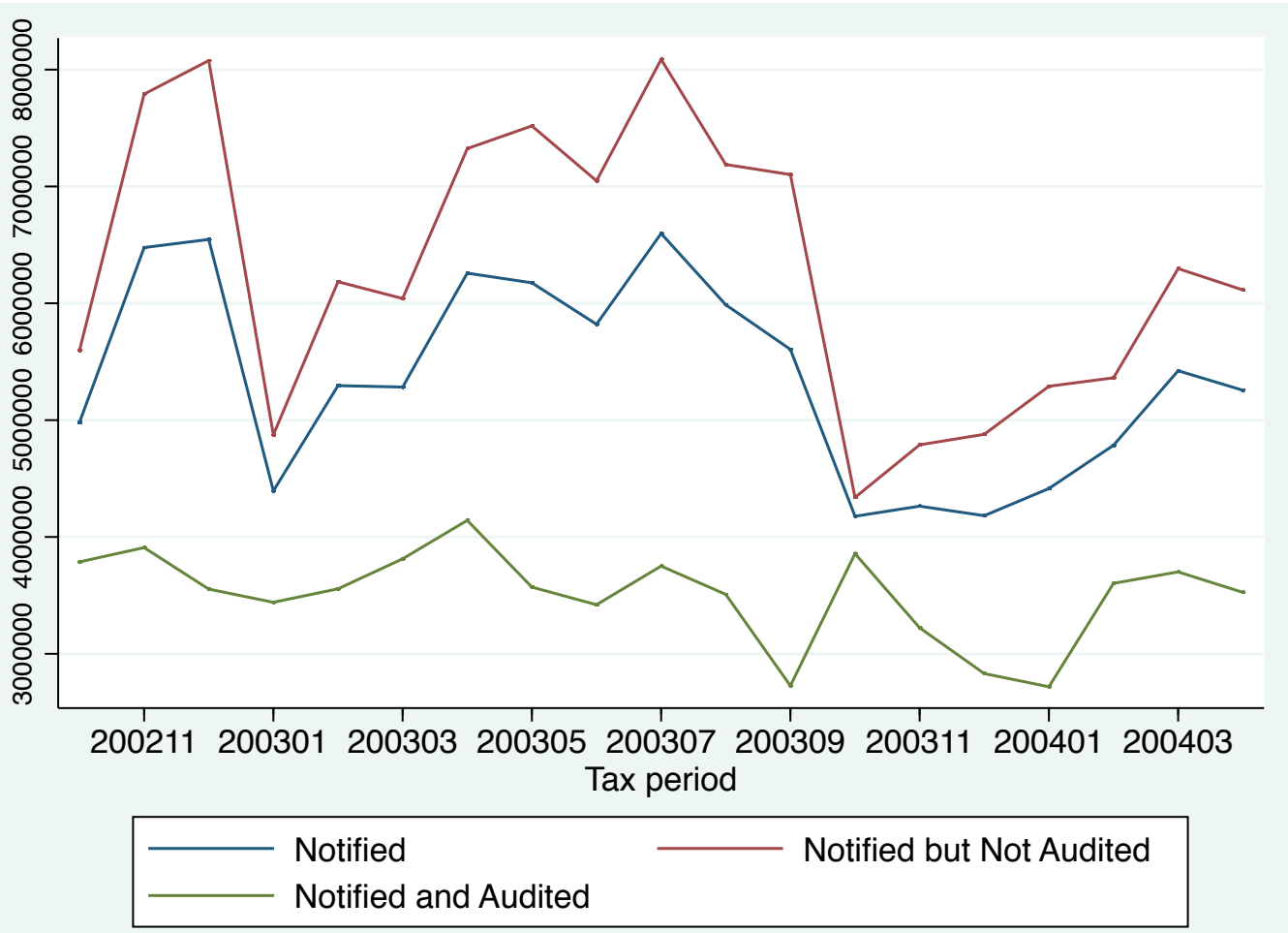

Figure 2 shows the monthly diesel tax credits claimed by notified firms, separating them between audited and not audited. What the figures shows reinforces the previous conclusion in the sense that the effect of the letter on all treated firms is what is being identified in the regressions, even though an additional later effect from auditing cannot be ruled out.

\section{Conclusions}

A differential diesel tax treatment in Chile creates incentives for firms to use "tax exempted" diesel in activities requiring "non tax exempted" diesel. This might be particularly easy to do for multi-products firms using diesel for several activities, allowing them to evade diesel taxes by claiming a larger amount of tax credits than what is legally allowed.

In an attempt to reduce the potential evasion of diesel taxes and improve tax enforcement, the Chilean IRS sent a letter to some firms asking to voluntarily report more details of every diesel transaction during the previous year. In this work we evaluate the impact of the letter on firms' behavior. The results show a significant impact of the letter sent by the IRS in reducing the amount of diesel tax credits claimed by firms. On average, treated 
firms reduce their tax credits claims by around $10 \%$ after receiving the letter. The results are consistent with previous results in the literature showing that just receiving a letter from the IRS has an impact on tax compliance because it causes a substantial increase in the perceived detection risk. In that sense, the results show that the IRS in Chile can successfully reduce diesel tax evasion by affecting firms' perceived cost of non-compliance. It would be important to consider in future research what happens in the long run. It could be possible that future letters would not have the same effect or even that the effect of the letter fades out in time and firms go back to their over-claiming practice.

Furthermore, the reduction in tax credits claims indirectly shows the existence of evasion in the diesel tax in Chile. The reason is that if there were no tax evasion, the diesel tax credits claims would not have been affected by the IRS notification letter. Therefore, the substantial impact the letter had on diesel credit claims can be interpreted as evidence of tax evasion through diesel tax credits over claiming.

\section{References}

Agha, A. and J. Haughton (1996), "Designing VAT Systems: Some Efficiency Considerations", The Review of Economics and Statistics 78(2).

Allingham, Michael G., and Agnar Sandmo (1972), "Income Tax Evasion: A Theoretical Analysis." Journal of Public Economics 1.

Andreoni, J., B. Erard, and J. Feinstein (1998), "Tax Compliance”, Journal of Economic Literature 36.

Caliendo, M. and S. Kopeinig (2008), "Some Practical Guidance for the Implementation of Propensity Score Matching", Journal of Economic Surveys 22(1).

Christian (1994), "Voluntary Compliance with the Individual Income Tax: Results from the 1988 TCMP Study”, in the IRS Research Bulletin, 1993/1994, Publication 1500 (Rev. 9-94), 35-42. Internal Revenue Service, Washington, D.C. 
Dehejia, R.H. and S. Wahba (1999), "Causal Effects in Nonexperimental Studies: Reevaluating the Evaluation of Training Programs", Journal of the American Statistical Association 94(448).

Dehejia, R.H. and S. Wahba (2002), "Propensity Score-Matching Methods for Nonexperimental Causal Studies", The Review of Economics and Statistics 84(1).

Erard, B. (1992), “The Influence of Tax Audits on Reporting Behavior”, in Joel Slemrod (ed.), Why people pay taxes: Tax compliance and enforcement, University of Michigan Press, Ann Arbor.

Fellner, G., R. Sausgruber, and C. Traxler (2009), "Testing Enforcement Strategies in the Field: Legal Threat, Moral Appeal and Social Information”, CESifo working paper No. 2787.

Imbens, G, and J. Wooldridge (2009), "Recent Developments in the Econometrics of Program Evaluation”, Journal of Economic Literature 47(1).

Imbens, G., D. Rubin, and B. Sacerdote (2001), "Estimating the Effect of Unearned Income on Labor Supply, Earnings, Savings, and Consumption: Evidence from a Survey of Lottery Players", American Economic Review 91(4).

Kopczuk, W. and J. Slemrod (2006), "Putting Firms into Optimal Tax Theory", AEA Papers and Proceedings 96(2).

Kleven, H.J., M.B. Knudsen, C.T. Kreiner, S. Pedersen, and E. Saez (2011), "Unwilling or Unable to Cheat: Evidence from a Tax Audit Experiment in Denmark", Econometrica 79(3).

Kepler, S. and D. Nagin (1989), "The Anatomy of Tax Evasion", Journal of Law and Economics 5(1).

Long, S. and R. Schwartz (1987), "The Impact of IRS Audits on Taxpayer Compliance: A Field Experiment in Specific Deterrence" in Annual Law and Society Association Meeting, Washington, D.C. 
Long, S. and J.A. Swingden (1990), "The Role of Third-Party Information Reporting and Compliance", in Research Conference Report, How Do We Affect Taxpayer Behavior?, Internal Revenue Service Document 7302 (3-91), Washington, D.C.

Marion, J., and E. Muehlegger (2008), "Measuring Illegal Activity and the Effects of Regulatory Innovation: Tax Evasion and the Dyeing of Untaxed Diesel”, Journal of Political Economy 116(41).

Pomeranz, Dina (2011), "No Taxation Without Information: Deterrence and SelfEnforcement in the Value Added Tax." Working Paper, Harvard Business School.

Sheffrin, S.M. and R.K. Triest (1992), "Can Brute Deterrence Backfire? Perceptions and Attitudes in Taxpayer Compliance", in Joel Slemrod (ed.) Why People Pay Taxes: Tax Compliance and Enforcement, University of Michigan Press, Ann Arbor.

Slemrod, J., M. Blumenthal, and C. Christian (2001), "Taxpayer Response to an Increased Probability of Audit: Evidence from a Controlled Experiment in Minnesota", Journal of Public Economics 79(3).

Wenzel, M., and N. Taylor (2004), "An Experimental Evaluation of Tax-Reporting Schedules: A Case of Evidence-Based Tax Administration", Journal of Public Economics $88(12)$. 
Table 1: Mean Characteristics

\begin{tabular}{|c|c|c|c|c|c|c|c|c|}
\hline & \multicolumn{2}{|c|}{$\begin{array}{c}\text { All } \\
\mathrm{N}=3,461\end{array}$} & \multicolumn{2}{|c|}{$\begin{array}{c}\text { Not Notified } \\
\mathrm{N}=3,356\end{array}$} & \multicolumn{2}{|c|}{$\begin{array}{l}\text { Notified } \\
\mathrm{N}=105\end{array}$} & \multicolumn{2}{|c|}{$\begin{array}{c}\text { Difference } \\
N=3,461\end{array}$} \\
\hline & [1] & [2] & [3] & [4] & [5] & [6] & [7] & {$[8]$} \\
\hline & Mean & Std. Desv. & Mean & Std. Desv. & Mean & Std. Desv. & Mean & t test \\
\hline \multicolumn{9}{|l|}{ Firm Characteristics } \\
\hline Number Activities & 2.14 & 1.58 & 2.12 & 1.56 & 2.78 & 2.23 & -0.66 & -4.22 \\
\hline Construction & 0.06 & 0.24 & 0.05 & 0.22 & 0.32 & 0.47 & -0.27 & -11.90 \\
\hline Transport & 0.77 & 0.42 & 0.78 & 0.41 & 0.35 & 0.48 & 0.43 & 10.46 \\
\hline Manufacturing & 0.11 & 0.32 & 0.11 & 0.32 & 0.17 & 0.38 & -0.06 & -1.86 \\
\hline Commerce & 0.06 & 0.23 & 0.05 & 0.23 & 0.15 & 0.36 & -0.10 & -4.30 \\
\hline Very Small Firm & 0.29 & 0.46 & 0.30 & 0.46 & 0.00 & 0.00 & 0.30 & 6.75 \\
\hline Small Firm & 0.47 & 0.50 & 0.49 & 0.50 & 0.05 & 0.21 & 0.44 & 8.97 \\
\hline Medium Firm & 0.14 & 0.34 & 0.13 & 0.34 & 0.30 & 0.46 & -0.16 & -4.87 \\
\hline Large Firm & 0.10 & 0.30 & 0.08 & 0.27 & 0.66 & 0.48 & -0.58 & -20.80 \\
\hline Age between 0 and 2 & 0.02 & 0.15 & 0.03 & 0.16 & 0.00 & 0.00 & 0.03 & 1.65 \\
\hline Age between 2 and 4 & 0.16 & 0.37 & 0.16 & 0.37 & 0.17 & 0.38 & -0.01 & -0.23 \\
\hline Age between 5 and 6 & 0.12 & 0.33 & 0.13 & 0.33 & 0.10 & 0.29 & 0.03 & 0.92 \\
\hline Age between 7 and 10 & 0.14 & 0.35 & 0.14 & 0.35 & 0.10 & 0.31 & 0.04 & 1.15 \\
\hline Older than 10 & 0.54 & 0.50 & 0.54 & 0.50 & 0.63 & 0.49 & -0.09 & -1.76 \\
\hline Accrual Accounting & 0.56 & 0.50 & 0.55 & 0.50 & 1.00 & 0.00 & -0.45 & -9.25 \\
\hline Cash Reporting & 0.00 & 0.03 & 0.00 & 0.03 & 0.00 & 0.00 & 0.00 & 0.35 \\
\hline Presumptive Tax & 0.34 & 0.47 & 0.35 & 0.48 & 0.00 & 0.00 & 0.35 & 7.48 \\
\hline \multicolumn{9}{|l|}{ Monthly Data } \\
\hline VAT repoted $(\log )$ & 10.44 & 5.57 & 10.46 & 5.47 & 9.58 & 8.00 & 0.89 & 5.33 \\
\hline Diesel Tax Credit (log) & 11.23 & 1.81 & 11.12 & 1.70 & 14.92 & 1.20 & -3.80 & -75.42 \\
\hline
\end{tabular}


Table 2: Mean Characteristics by Treatment Status

\begin{tabular}{|c|c|c|c|c|c|c|}
\hline & \multicolumn{2}{|c|}{$\begin{array}{c}\text { Control (1) } \\
\mathrm{N}=464\end{array}$} & \multicolumn{2}{|c|}{$\begin{array}{l}\text { Treatment (2) } \\
\mathrm{N}=105\end{array}$} & \multicolumn{2}{|c|}{$\begin{array}{c}\text { Difference (1)-(2) } \\
\mathrm{N}=569\end{array}$} \\
\hline & Mean & Std. Desv. & Mean & Std. Desv. & Mean & ttest \\
\hline \multicolumn{7}{|l|}{ Firm Characteristics } \\
\hline Number Activities & 2.526 & 1.672 & 2.781 & 2.232 & -0.255 & -1.321 \\
\hline Construction & 0.123 & 0.329 & 0.324 & 0.470 & -0.201 & -5.183 \\
\hline Transport & 0.612 & 0.488 & 0.352 & 0.480 & 0.260 & 4.941 \\
\hline Manufacturing & 0.155 & 0.362 & 0.171 & 0.379 & -0.016 & -0.412 \\
\hline Commerce & 0.110 & 0.313 & 0.152 & 0.361 & -0.042 & -1.219 \\
\hline Small Firm & 0.334 & 0.472 & 0.048 & 0.214 & 0.286 & 6.073 \\
\hline Medium Firm & 0.416 & 0.493 & 0.295 & 0.458 & 0.121 & 2.293 \\
\hline Large Firm & 0.250 & 0.433 & 0.657 & 0.477 & -0.407 & -8.528 \\
\hline Age between 2 and 4 & 0.175 & 0.380 & 0.171 & 0.379 & 0.003 & 0.077 \\
\hline Age between 5 and 6 & 0.116 & 0.321 & 0.095 & 0.295 & 0.021 & 0.618 \\
\hline Age between 7 and 10 & 0.144 & 0.352 & 0.105 & 0.308 & 0.040 & 1.066 \\
\hline Older than 10 & 0.565 & 0.496 & 0.629 & 0.486 & -0.064 & -1.196 \\
\hline \multicolumn{7}{|l|}{ Monthly Data } \\
\hline VAT repoted $(\log )$ & 10.530 & 6.717 & 9.628 & 7.983 & 0.902 & 3.386 \\
\hline Diesel Tax Credit (log) & 13.223 & 1.176 & 14.939 & 1.193 & -1.717 & -38.104 \\
\hline
\end{tabular}

Note: Table shows descriptive statistics of fimrs that reported diesel tax credit every month and which are in the common suport according to the propensity score. Very small firms, firms using presumptive tax or cash report, and firms between 1 and 24 month are excluded from the propensity score since none of the notified firms with positive diesel tax credit every month has these characteristics. 
Table 3: Diesel Tax Credit (Random Effects Panel)

(1)

\begin{tabular}{|c|c|c|c|}
\hline \multicolumn{4}{|l|}{ Log Diesel Tax Credit } \\
\hline \multirow[t]{2}{*}{ Notification } & $1.704 * *$ & $1.704 * *$ & $1.209 * *$ \\
\hline & $(0.117)$ & $(0.117)$ & $(0.112)$ \\
\hline \multirow[t]{2}{*}{ After Letter } & $0.107 * *$ & $0.160 * *$ & $0.121 * *$ \\
\hline & $(0.0117)$ & $(0.0250)$ & $(0.0243)$ \\
\hline \multirow[t]{2}{*}{ Notification*After Letter } & $-0.0993 * *$ & $-0.0993 * *$ & $-0.0993^{* *}$ \\
\hline & $(0.0272)$ & $(0.0271)$ & $(0.0272)$ \\
\hline \multirow[t]{2}{*}{ Number of Activities } & & & 0.0309 \\
\hline & & & $(0.0226)$ \\
\hline \multirow[t]{2}{*}{ Transport } & & & 0.131 \\
\hline & & & $(0.129)$ \\
\hline \multirow[t]{2}{*}{ Manufacturing } & & & 0.178 \\
\hline & & & $(0.155)$ \\
\hline \multirow[t]{2}{*}{ Construction } & & & -0.0113 \\
\hline & & & $(0.154)$ \\
\hline \multirow[t]{2}{*}{ Small Firm } & & & $-1.469 * *$ \\
\hline & & & $(0.113)$ \\
\hline \multirow[t]{2}{*}{ Medium Firm } & & & $-0.830 * *$ \\
\hline & & & $(0.101)$ \\
\hline \multirow[t]{2}{*}{ Age between 2 and 4} & & & -0.119 \\
\hline & & & $(0.110)$ \\
\hline \multirow[t]{2}{*}{ Age between 5 and 6} & & & 0.0682 \\
\hline & & & $(0.131)$ \\
\hline \multirow[t]{2}{*}{ Age between 7 and 10} & & & -0.0481 \\
\hline & & & $(0.120)$ \\
\hline \multirow[t]{2}{*}{ VAT reported $(\log )$} & & & 0.00105 \\
\hline & & & $(0.00103)$ \\
\hline \multirow[t]{2}{*}{ Constant } & $13.22 * *$ & $13.14 * *$ & $13.88 * *$ \\
\hline & $(0.0504)$ & $(0.0580)$ & $(0.154)$ \\
\hline Monthly Dummies & No & Yes & Yes \\
\hline Year Dummies & No & Yes & Yes \\
\hline Observations & 9104 & 9104 & 9104 \\
\hline Number of firms & 569 & 569 & 569 \\
\hline $\mathrm{R} 2$ & 0.230 & 0.231 & 0.395 \\
\hline Wald & 286.7 & & \\
\hline
\end{tabular}

Note: Table shows regressions for firms that reported diesel tax credit every month and which are in the common suport according to the propensity score. The estimations is based on monthly data from January 2003 to April 2004. Standard errors in parentheses $* \mathrm{p}<0.1 * * \mathrm{p}<0.05$ 
Table 4: Diesel Tax Credit (Heckman Selection)

(1)

(2)

(3)

Log Diesel Tax Credit

After Letter

$0.101 * * \quad 0.128 * * \quad 0.129 * *$

Notification*After Letter

$\begin{array}{lll}(0.0118) & (0.0154) \quad(0.0150)\end{array}$

$-0.0674 * * \quad-0.0676 * * \quad-0.0734 * *$

Number of Activities

$(0.0306) \quad(0.0308)$

$(0.0275)$

$-0.277 * *$

$(0.00340)$

Transport

$1.698 * *$

$(0.0223)$

Manufacturing

$1.802 * *$

$(0.0267)$

Construction

$-2.067 * *$

$(0.0304)$

Small Firm

$9.413 * *$

$(0.0995)$

Medium Firm

$0.0832 * *$

$(0.0158)$

Age between 2 and 4

$-0.0308 *$

$(0.0171)$

Age between 5 and 6

$0.319 * *$

$(0.0164)$

Age between 7 and 10

$0.111^{* *}$

$(0.0148)$

VAT reported $(\log )$

0.00118

$(0.00107)$

Constant

$14.49 * * \quad 14.43 * *$

$18.05^{* *}$

(0.0107)

$(0.0235)$

(0.0403)

\section{Letter}

Diff. Diesel Tax Credit 2002-2001

$$
2.06 \mathrm{e}-\quad 2.06 \mathrm{e}-\quad 2.06 \mathrm{e}-
$$

$08 * * \quad 08 * * \quad 08 * *$

$$
(3.10 \mathrm{e}-09) \quad(3.10 \mathrm{e}-09) \quad(3.10 \mathrm{e}-09)
$$

Inverse Mills Ratio (Lambda)

$-0.182 * * \quad-0.182 * *$

$-1.434 * *$

$\begin{array}{lll}(0.00172) & (0.00173) & (0.0124)\end{array}$

Observations

9104

9104

9104

Number of Firms

569

569

569

R2

0.234

0.235

0.469

Wald

13566.1

13668.5

67808.1

Note: Table shows regressions for firms that reported diesel tax credit every month and which are in the common suport according to the propensity score. The estimations is based on monthly data from January 2003 to April 2004. Standard errors in parentheses * p<0.1** $\mathrm{p}<0.05$ 
Table 5: Heterogeneous Effects by Industry

\begin{tabular}{|c|c|c|}
\hline & $(1)$ & $(2)$ \\
\hline \multicolumn{3}{|l|}{ Log Diesel Tax Credit } \\
\hline Notification & $\begin{array}{l}1.242^{* *} \\
(0.273)\end{array}$ & \\
\hline \multirow{2}{*}{ After Letter } & $0.100^{* *}$ & $0.115^{* *}$ \\
\hline & $(0.0412)$ & $(0.0445)$ \\
\hline \multirow[t]{2}{*}{ Notification*After Letter } & $-0.223^{* *}$ & $-0.188 * *$ \\
\hline & $(0.0721)$ & $(0.0570)$ \\
\hline \multirow[t]{2}{*}{ After*Trans } & 0.0283 & 0.0366 \\
\hline & $(0.0383)$ & $(0.0436)$ \\
\hline \multirow{2}{*}{ Notification*Transport } & -0.288 & $0.765^{* *}$ \\
\hline & $(0.317)$ & $(0.0262)$ \\
\hline \multirow{2}{*}{ Notif*After Letter*Transport } & $0.171^{* *}$ & $0.137^{* *}$ \\
\hline & $(0.0845)$ & $(0.0667)$ \\
\hline \multirow[t]{2}{*}{ After*Manufacturing } & -0.0359 & -0.0276 \\
\hline & $(0.0461)$ & $(0.0498)$ \\
\hline \multirow[t]{2}{*}{ Notification*Manufacturing } & 0.506 & $0.305^{* *}$ \\
\hline & $(0.370)$ & $(0.0670)$ \\
\hline \multirow[t]{2}{*}{ Notif*After Letter*Manufacturing } & 0.0654 & 0.0307 \\
\hline & $(0.0980)$ & $(0.114)$ \\
\hline \multirow[t]{2}{*}{ After*Construction } & -0.0105 & -0.00219 \\
\hline & $(0.0485)$ & $(0.0601)$ \\
\hline \multirow[t]{2}{*}{ Notification*Construction } & -0.0446 & $1.040^{* *}$ \\
\hline & $(0.341)$ & $(0.0315)$ \\
\hline \multirow{2}{*}{ Notif*After Letter*Construction } & $0.191^{* *}$ & $0.156^{* *}$ \\
\hline & $(0.0904)$ & $(0.0781)$ \\
\hline \multirow[t]{2}{*}{ Number of Activities } & 0.0356 & $-0.265^{* *}$ \\
\hline & $(0.0227)$ & $(0.00428)$ \\
\hline \multirow{2}{*}{ Transport } & 0.144 & $1.441^{* *}$ \\
\hline & $(0.145)$ & $(0.0314)$ \\
\hline \multirow[t]{2}{*}{ Manufacturing } & 0.0926 & $1.662^{* *}$ \\
\hline & $(0.174)$ & $(0.0345)$ \\
\hline Construction & -0.0150 & $-2.332^{* *}$ \\
\hline & $(0.183)$ & $(0.0404)$ \\
\hline Small Firm & $-1.477^{* *}$ & $8.914^{* *}$ \\
\hline & $(0.113)$ & $(0.0993)$ \\
\hline Medium Firm & $-0.828^{* *}$ & $0.145^{* *}$ \\
\hline & $(0.101)$ & $(0.0181)$ \\
\hline Age between 2 and 4 & -0.105 & $-0.0411^{* *}$ \\
\hline & $(0.110)$ & $(0.0130)$ \\
\hline Age between 5 and 6 & 0.0767 & $0.295^{* *}$ \\
\hline & $(0.131)$ & $(0.0201)$ \\
\hline Age between 7 and 10 & -0.0315 & $0.123^{* *}$ \\
\hline & $(0.120)$ & $(0.0156)$ \\
\hline VAT Reported (log) & 0.00112 & 0.00113 \\
\hline & $(0.00103)$ & $(0.00138)$ \\
\hline Constant & $13.87^{* *}$ & $17.76^{* *}$ \\
\hline & $(0.163)$ & $(0.0452)$ \\
\hline Letter & & \\
\hline Diff. Diesel Tax Credit 2002-2001 & & $2.06 \mathrm{e}-08^{* *}$ \\
\hline & & $(3.10 \mathrm{e}-09)$ \\
\hline Inverse Mills Ratio (Lambda) & & $-1.443^{* *}$ \\
\hline & & $(0.0150)$ \\
\hline Effect Notif*After* Transport & -0.0512 & -0.0512 \\
\hline & $(0.04399)$ & $(0.0349)$ \\
\hline Effect Notif*After*Manufacturing & $-0.1572^{* *}$ & -0.1572 \\
\hline & $(0.0663)$ & $(0.1041)$ \\
\hline Effect Notif*After*Construction & -0.03187 & -0.0318 \\
\hline & $(0.0545)$ & $(0.0547)$ \\
\hline Monthly Dummies & Yes & Yes \\
\hline Year Dummies & Yes & Yes \\
\hline Observations & 9104 & 9104 \\
\hline Number of firms & 569 & 569 \\
\hline $\mathrm{R} 2$ & 0.400 & 0.507 \\
\hline Wald & & 133255.6 \\
\hline
\end{tabular}


Table 6: False Experiment

(1)

\begin{tabular}{lc}
\hline Log Diesel Tax Credit & \\
After Letter & $0.0630^{* *}$ \\
& $(0.0288)$ \\
Notification*After Letter & 0.00115 \\
& $(0.0314)$ \\
Constant & $-0.141^{* *}$ \\
& $(0.0276)$ \\
\hline Letter & \\
& \\
Diff. Diesel Tax Credit 2002-2001 & $2.24 \mathrm{e}-$ \\
& $08^{* *}$ \\
Lambda (Inverse Mills Ratio) & $(1.83 \mathrm{e}-09)$ \\
& $-0.426^{* *}$ \\
Monthly Dummies & $(0.00381)$ \\
Year Dummies & Yes \\
Observations & Yes \\
Number of Firms & 6259 \\
R2 & 569 \\
Wald & 0.334 \\
\end{tabular}

Note: Table shows regressions for firms that reported diesel tax credit every month and which are in the common suport according to the propensity score. The estimations is based on monthly data from October 2002 to August 2003. The false experiment considered march 2003 as the month of notification. Standard errors in parentheses * $\mathrm{p}<0.1 * * \mathrm{p}<0.05$ 
Table 7: VAT (Random Effects Panel)

\begin{tabular}{|c|c|c|c|}
\hline & (1) & (2) & (3) \\
\hline \multicolumn{4}{|l|}{ Log VAT Reported } \\
\hline & $\begin{array}{l}-0.885 \\
(0.541)\end{array}$ & $\begin{array}{l}-0.885 \\
(0.541)\end{array}$ & $\begin{array}{l}-0.742 \\
(0.588)\end{array}$ \\
\hline After Letter & $\begin{array}{l}0.0812 \\
(0.122)\end{array}$ & $\begin{array}{c}0.255 \\
(0.284)\end{array}$ & $\begin{array}{l}1.191 * * \\
(0.284)\end{array}$ \\
\hline Notification*After Letter & $\begin{array}{c}-0.0183 \\
(0.285)\end{array}$ & $\begin{array}{c}-0.0183 \\
(0.284)\end{array}$ & $\begin{array}{c}-0.0131 \\
(0.284)\end{array}$ \\
\hline Number of Activities & & & $\begin{array}{l}-0.276^{* *} \\
(0.114)\end{array}$ \\
\hline Transport & & & $\begin{array}{l}2.936 * * \\
(0.652)\end{array}$ \\
\hline Manufacturing & & & $\begin{array}{l}1.033 \\
(0.783)\end{array}$ \\
\hline Construction & & & $\begin{array}{l}2.741 * * \\
(0.776)\end{array}$ \\
\hline Small Firm & & & $\begin{array}{l}-0.352 \\
(0.589)\end{array}$ \\
\hline Medium Firm & & & $\begin{array}{l}0.503 \\
(0.516)\end{array}$ \\
\hline Age between 2 and 4 & & & $\begin{array}{l}-0.208 \\
(0.556)\end{array}$ \\
\hline Age between 5 and 6 & & & $\begin{array}{l}0.453 \\
(0.661)\end{array}$ \\
\hline Age between 7 and 10 & & & $\begin{array}{l}-0.0525 \\
(0.604)\end{array}$ \\
\hline Diesel Tax Credit (log) & & & $\begin{array}{l}0.0528 \\
(0.100)\end{array}$ \\
\hline Constant & $\begin{array}{l}10.53 * * \\
(0.232)\end{array}$ & $\begin{array}{l}9.907 * * \\
(0.439)\end{array}$ & $\begin{array}{l}6.571 * * \\
(1.627)\end{array}$ \\
\hline Monthly Dummies & No & Yes & Yes \\
\hline Year Dummies & No & Yes & Yes \\
\hline Observations & 9104 & 9104 & 9104 \\
\hline Number of firms & 569 & 569 & 569 \\
\hline $\mathrm{R} 2$ & 0.00246 & 0.00413 & 0.0363 \\
\hline Wald & 3.377 & & \\
\hline
\end{tabular}

Note: Table shows regressions for firms that reported diesel tax credit every month and which are in the common suport according to the propensity score. The estimations is based on monthly data from January 2003 to April 2004. Standard errors in parentheses $* \mathrm{p}<0.1 * * \mathrm{p}<0.05$ 
Table 8: VAT (Heckman Selection)

(1)

Log VAT Reported

After Letter

Notification*After Letter

Number of Activities

Transport

Manufacturing

Construction

Small Firm

Medium Firm

Age between 2 and 4

Age between 5 and 6

Age between 7 and 10

Diesel Tax Credit (log)

0.0816
$(0.0958)$
-0.0207
$(0.287)$

0.0631

$(0.170)$

$-0.0207$

(0.351)

$(0.279)$

$0.418 * *$

$(0.0751)$

$-0.549$

(0.388)

$-2.586 * *$

(0.384)

$7.397 * *$

(0.555)

$-24.22 * *$

(2.320)

$-1.813 * *$

(0.230)

$-0.375 * *$

(0.148)

$-0.119$

(0.193)

$-0.438 * *$

(0.165)

0.107

(0.140)

Constant

$10.25 * * \quad 9.816^{* *}$

$-1.506$

(0.102)

(0.195)

(2.729)

\section{Letter}

Diff. Diesel Tax Credit 20022001

$\begin{array}{ccc}2.06 \mathrm{e}- & 2.06 \mathrm{e}- & 2.06 \mathrm{e}- \\ 08 * * & 08 * * & 08 * *\end{array}$

\begin{tabular}{lccc} 
& $(3.10 \mathrm{e}-09)$ & $(3.10 \mathrm{e}-09)$ & $(3.10 \mathrm{e}-09)$ \\
Inverse Mills Ratio (Lambda) & 0.0231 & 0.0231 & $3.080 * *$ \\
& $(0.0162)$ & $(0.0151)$ & $(0.316)$ \\
\hline Observations & 9104 & 9104 & 9104 \\
Number of Firms & 569 & 569 & 569 \\
R2 & 0.000116 & 0.00178 & 0.0504 \\
Wald & 3.923 & 22.86 & 1382.1 \\
\hline
\end{tabular}

Note: Table shows regressions for firms that reported diesel tax credit every month and which are in the common suport according to the propensity score. The estimations is based on monthly data from January 2003 to April 2004. Standard errors in parentheses $* \mathrm{p}<0.1 * *$ $\mathrm{p}<0.05$ 